\title{
Probe into the Rent-Seeking Issue in China's Security Issuance
}

\author{
Ruqi Zeng \\ Business School, Shenzhen University, Shenzhen 518060, China \\ E-mail: s6020293@szu.edu.cn
}

\begin{abstract}
The security market has developed fast in China. It has spent ten years in completing the course that was completed by countries with perfect capitalism market economy in one hundred years. Because the development of market system fails to catch up with the fast development of security market, lots of issues appear. Focusing on the imperfection of security issuance market, this paper tries to probe into the relatively severe rent-seeking issue and tempts to provide with suggestions for reform.
\end{abstract}

Keywords: Rent-seeking, Security issuance, Information disclosure, Government supervision and regulation, Approval system, Register system

\section{Introduction}

What is rent-seeking? Rent means money, profit, and benefit. Rent-seeking, in short, is to pursue for economic benefit. The generation of rent-seeking is based on the behavior of "economic man" who may take advantages over the imperfect parts in system, laws, and policies and perform rent-seeking in order to maximize their interests. Because the security market in China develops fast, the legislation system can not keep the same pace with the economic growth during certain period. The imperfect parts objectively cause the rent-seeking act in security market.

The popularization of rent-seeking exerts huge harmful effects on the development of security market, increasing the financial risk. Therefore, it is a primary issue for the reform of security issuance market properly dealing with the rent-seeking act. What aspects do the security issuance's rent-seeking issue exists in China? And what's the reason? Based on the discussion of these questions, this paper will put forward suggestions for policy reform.

\section{The introduction of the issue ------ the rent-seeking act in issuance market}

\subsection{The rent-seeking act in gaining issuance qualification ------ make fake qualification in order to enter the market}

Undoubtedly, in such a bull market with high earnings per share (EPS), all companies, even companies in lose, can gain numerous benefits, only if they can enter the market. Once they successfully enter the market, they can achieve directly finance, transfer the operation system, build corporate image, and so on. Therefore, many unlisted companies strive to enter the market to "collect money". However, the "approval system" in China is different from the "registered system" in America. It is not the market that determines which one is the best or which one the worst. Therefore, a great number of companies have to think it over before they really hand in applications although they want to enter the market but be afraid of numerous "rules". Besides, under the present system in the security issuance market, all companies have to compete for relatively few opportunities of entering the market. With the condition of unbalanced market, some companies try to obtain the high "rent" for stock issuance by all kinds of means in order to seek for the qualification of stock issuance. In recent years, this phenomenon is common. For example, Shenzhen Huapeng Certified Public Accountants provided with audition reports that were inconsistent with the facts for listed companies. Guangdong Dazheng Associated Asset Evaluation Co. Ltd. presented the asset evaluation report that was inconsistent with facts. Guangdong Mingda Lawyer Office presented the legal report that was inconsistent with facts. Southern Security Co. Ltd. took a part in composing issuance application report that was inconsistent with facts. To fake qualification to enter the market is the most severe issue of rent-seeking in present issuance market.

\subsection{The rent-seeking act in pricing the issuance price ------ wrong profits and high prices in issuing stock}

In order to obtain excessive profits and seek for high rents, many listed companies make fake reports and profits. For example, "Macat" made up a fixed asset of 90.74 million Hongkong dollars and a profit of 93.20 million Hongkong dollars in order to meet the requirements for security market. Hongguang Stock (600083) that listed in market in 1997 made fake financial reports, turning the losses into the profits in order to cheat for qualification of market entrance. In its report, it said: "the earnings per share (EPS) from 1994 to 1996 are respectively 0.38 Yuan, 0.491 Yuan, and 0.339 Yuan. Supported by researches on electric display components and technological strengths in production, the company focuses on enlarging the color kinescope project. In the process of extending the advantages in the dominant products, the company develops its business toward the field of display and other products, realizing a constant optimization of 
product structure. Research and develop the production of parts used in computer display. Aiming at achieving the effect of scale economy, the company will explore both domestic and international markets by reliable quality, excellent service, competitive price, and advantage of cost." But in fact, the company suffered from a huge loss in the first year when it listed in the market. The loss per share was 0.863 Yuan. In 1998, the loss was 1.442 Yuan per share. And the total loss reached 332 million Yuan. The loss in 1997 and 1998 exceeded the total capitals collected by listing in market. From the table 1 (Mingxian Liu, 2005), the price of the new stock in its issuance includes a large rent. The rent-seeking issue is noticeable.

\section{Analysis on the issue ------ reason of the rent-seeking act}

In author's opinion, the reason of the rent-seeking act in security issuance market is that the reform of supervision and regulation system can not catch up with the growth of security market in essence. And the exterior reason is the imperfect parts in present information disclosure system.

\subsection{The rent-seeking caused by the approval system}

Next, we analyze this issue based on the model in the figure 1 (Li Jia, 2006).

(1) The pre-assumption for the approval system is that investors can not understand completely the stock-inviting introduction and can not protect their profits by making correct judge. Therefore, the government helps investors to escape form risks by authorizing the issuance of stock.

(2) If companies that prepared for listing in market are not qualified, they will have to compare the rent-seeking costs and the profits and make balance in front of the strict approval system. As a result, the motive of rent-seeking appears.

(3) Many imperfect rules exist in present approval system. Companies may gain the approval by dealing with public relations and spending amount of money (table 2).

(4) Although companies that performed bad aim at collecting money by issuing stocks, they have already gained approval of the government. At the very beginning of their stock issuance, many investors buy in their stocks. However, after a period, these stocks can not survive from the market. The price will decrease sharply.

(5) The approval system causes such a result that is completely contrary with the original intention. The government can not protect the investors but increase their risks.

(6) The approval system leads to two exterior effects. A: interfere with the market price and cause confusion in market; B: cause conflicts and decrease government's trustiness.

\subsection{The imperfect parts in information disclosure system}

The imperfect parts in information disclosure system lead to the "adverse selection" and "moral risk" that lead to the rent-seeking act. The "adverse selection" refers to the distorted market resource allocation because of information asymmetry. The "moral risk" refers that people enjoy their interests but impute costs to others, causing the possibility of others' loss (figure 2).

(1) The disclosed accounting information is not true.

The untruth of information includes two aspects. One is to make up fake data purposefully, such as the exaggerated profits. Some companies even turn the loss into the profits. The other is to use improper accounting method purposefully. Then the accounting information can not reflect the truth effectively. By this way, these companies can successfully cheat the investors. Escaping from the aspect of professional morals and laws, viewing from an economic angle, an economic relationship exists in the accounting agencies and listed companies. In other words, listed companies are employers. Accounting agencies gain return from listed companies by providing with professional services. Accountants audit listed companies and present certificates. However, these accountants are also economic men. They pursue the maximum of individual profits. As a result, the moral risk is coming. Accountants will have the motive of rent-seeking.

(2) The disclosed accounting information is not complete and timely.

Although Security and Exchange Board regulates fixed forms and contents for the disclosure of accounting information, many listed companies do not obey these rules completely. For example, as listed companies are in loss, they may declare that it is the macro factor that causes the loss for the sake of their own interests. If it is the macro factor that brings about interests, listed companies may declare that it is their excellent performance that leads to the profits. If the performance is worse, listed companies will delay to deliver the report. It is hard for the security supervising institution to find out the truth in time and ask them behave themselves. Therefore, listed companies will choose to disclose the information that is good for them, but investors can not know the real accounting information of listed companies. Information asymmetry causes the "adverse selection" that provides with conditions for the appearance of rent-seeking act. 
(3) The unexpected disclosure of information is grave.

As listed companies disclose their accounting information, many subjects participate in this process, including the Security Regulatory Commission, the Security and Exchange Board, and media. Multiple channels make it inevitable to disclose unexpected information. Although the law forbids workers in the securities field to join in the stock market, it is impossible from a view of economics. It is a must for workers in this field to seek rent in order to pursue maximum individual profits. Although workers in the securities field do not directly join in the stock market, they can provide with useful guidance for friends and relatives because they master the information that can be turned into economic profits effectively. Unexpected information disclosure, as a public secret, makes the securities market into a great "rent-seeking field".

\section{Problem solving ------ suggestions for reform}

Based on analysis above, we know the companies' rent-seeking act in security issuance and the reason. Therefore, we have to think about how to solve the rent-seeking issue and guarantee the healthy and stable development of stock market.

\subsection{Perform the recommend system properly}

At the present, the imperfect parts in the approval system are due to the imperfectness of the recommender system. Firstly, the costs of recommenders' illegal action are low. Secondly, recommenders do not possess sufficient powers. Thirdly, the mechanism in which one institution shoulders both recommending and marketing responsibilities may lead to superficial supervision and examination. Because of the imperfect recommend system, as we transfer the supervision and examination from the government to the medium agency, the corruption is transferred at the same time. To perfect the recommend system, it is necessary to extend the recommend term and protect investors' interests. Recommenders still shoulder the guarantee responsibility for the information disclosure as companies enter the market. Impose severe punishment on recommenders who commit terrible mistakes and set up funds for recommender risk. Improve the ability of recommender keeping away from risks. Increase the opportunity cost for recommender's rent-seeking act. By these means, the rent-seeking acts can be reduced.

\subsection{Construct perfect supervision system and strike severely on the illegal act in information disclosure}

Proper information disclosure is the most important way to reduce rent-seeking act. To perfect the information disclosure system and execute system supervision, we should work hard in these aspects as follow (figure 3).

(1) Construct perfect supervision system and strike on illegal act of information disclosure

The confusion in the security issuance market is caused by the failure of executing the system supervision. There are no clear and complete financial rules, policies, and regulations to restrain the behavior of financial institutions, social medium agencies, listed companies, and investors. China does not have a supervision system that emphasizes on laws, media supervision, and self-restriction, what leads to sorts of illegal acts in information disclosure. At the same time, the weak punishment can not stop listed companies making up fake information because the profits gained from fake information are higher than the costs. Therefore, as we lay stresses on policies, we should emphasize on punishment. The business license of medium agencies that participate in making up fake information should be canceled. And they should shoulder not only economic responsibility but also criminal responsibility. By this way, the law and system can exert their threatening and warning effect.

(2) Enhance listed companies' internal governance and perfect the inner supervision

In China, the reform of stock mechanism in listed companies is not complete. Lots of problems exist in corporate governance. Although the supervision committee and the independent director serve as restriction mechanism, the division of labor is not very clear. And even the division conflicts with each other. The dual governance system does not exert positive effects on each other but weaken mutually. The independent director system has many shortcomings. Independent directors are famous people in the society. As independent directors in certain company, although they take high salaries from the company and sometimes have a look at the company, they do not understand the company's economic situation. Besides, they do not participate in the company's daily operation, what they know is coming from top managers in the company. It is impossible to ask these useless independent directors to supervise the governance of the company. To solve this problem, it is necessary to cope with the relationship between the supervision committee and the independent director properly, establishing their supervising responsibilities clearly. Enhance powerful supervision and regulation on the company internally.

(3) Improve the professional morals and the legal consciousness of security workers

Although thinking from the angle of "economic man", the rent-seeking is inevitable. But as a matter of fact, by long-term legal education and professional morals' cultivation, the principle of sincerity and credit and the principle of keeping the law in the security market may become popular. Like the mature security market in the west, the popularization of professional morals is more effective than self-restriction and laws. 


\subsection{Transfer from the "approval system" to the "register system" step by step}

The present recommend system performed by the government is better than the former pass system. But it still does not solve the essential problem in former approval system ------ the right ascription of issuing stock. From the table 1 above, under the approval system the issuance right is hold in the hand of government. If we do not turn the approval system into the register system, not returning the issuance right of stock back to the market, the recommend system still does not lay a finger on the most essential problem, what is merely a way of the Security Supervision and Regulation Committee transferring responsibilities to a lower level. The essence of solving the rent-seeking issue is to turn the approval system into the register system gradually.

Analyze the figure 4 that is different from the figure 1.

(1) In the register system, companies have to apply for stock issuance and register in security management institutions, and publicize all relevant information before they issue their stocks. It emphasizes on the principle of publicity. In other words, the companies must provide with real, objective, and comprehensive corporate materials. The security supervision and regulation institution merely examine the authenticity and the comprehensiveness of the application files provided by companies. Whether the stock is good or bad, it is the market to make the decision. Investors must protect their interests by themselves.

(2) The register system reflects the freedom of economy. Under this idea, only if a company publicizes its accounting information and its authenticity is checked by the security supervision and regulation institution, the company can issue its stock even if its performance is terrible. By this way, these kinds of companies have no motives of rent-seeking. Therefore, the rent-seeking act will be stopped from the systematic aspect.

(3) Investors have to make choice based on their thoughts and the information is publicized truthfully, comprehensively, exactly, and timely. Economics suppose everyone is rational. Everyone is seeking for maximum individual interests.

(4) As a result, we draw a conclusion that is completely different from the figure 1 ------ investors protect their interests successfully.

(5) At the same time, the exterior effects are also different from the table 1. It solves the rent-seeking issue and generates two exterior effects: A. Be good for market resource's optimal allocation; B. Improve the government's trustiness.

\section{References}

Bai, Yuqin. (2007). The system of recommenders in China's issuing securities. Journal of Shenzhen University (Humanities \& Social Sciences). No.3.

Gao, Minghua. \& Liu, Jinling. (2006). The power conflicts and the policy choices for the independent directors and board of supervisors. Journal of Graduate School of Chinese Academy of Social Sciences. No.6.

Hu, Haiou. (2003). A study on "adverse selection" and "moral risk". ShangHai Financial News.No.8

Jia, Li. (2006). An analysis on the institutional disadvantages of the approval system for stock issuance. Research on Financial Issue. No.3.

Liu, Mingxian. (2005). China security market's system economics analysis. Special Zone Economy. No.6.

Sun, Xiuhui. (2005). Problems in and countermeasures for the information disclosure of listed companies. Market Weekly \& Management Exploration. No.1.

Wang, Jin. (2002).Analysis on the examination and approval regulation for stock issuance. Financial Theory and Practice. No.9.

Xiong, Jianqing. (2002). A information economics analysis on China's security market. Journal of Nanjing Higher Finance College. No.4. 
Table 1. New stocks in market and their evaluated rents from 1990 to 2003.

\begin{tabular}{|l|l|l|l|}
\hline Year & $\begin{array}{l}\text { Collected capital } \\
(100 \text { million Yuan) }\end{array}$ & $\begin{array}{l}\text { Weighed average price in } \\
\text { issuing day/Issuing price (\%) }\end{array}$ & \\
\hline Rent (100 million Yuan) & $1990-1996$ & 1376.74 & 388 \\
\hline 1997 & 1293.82 & 160 & 2070.11 \\
\hline 1998 & 841.52 & 131 & 1093.98 \\
\hline 1999 & 944.56 & 120 & 1133.47 \\
\hline 2000 & 2103.08 & 154 & 3238.74 \\
\hline 2001 & 1252.34 & 143 & 1790.85 \\
\hline 2002 & 961.76 & 133 & 1279.14 \\
\hline 2003 & 1357.76 & 72 & 977.59 \\
\hline Total & 10131.58 & 163 & 16925.63 \\
\hline
\end{tabular}

Source: Calculated by data from China Statistics Yearbook 2000 and China Statistics Abstract 2001. Data between 2001 and 2003 are from the website of China Security Regulatory Commission.

Table 2. The estimated expenses used for public relations by companies in their issuance

\begin{tabular}{|c|c|c|c|c|c|c|c|}
\hline \multirow[t]{2}{*}{ Year } & \multirow{2}{*}{$\begin{array}{l}\text { New listed } \\
\text { companies } \\
\text { per year }\end{array}$} & \multicolumn{2}{|c|}{$\begin{array}{l}\text { Expenses used for public } \\
\text { relations per year }\end{array}$} & \multirow[t]{2}{*}{ Year } & \multirow{2}{*}{$\begin{array}{l}\text { New listed } \\
\text { companies } \\
\text { per year }\end{array}$} & \multicolumn{2}{|c|}{$\begin{array}{l}\text { Expenses used for public } \\
\text { relations per year }\end{array}$} \\
\hline & & Lowest & Highest & & & Lowest & Lowest \\
\hline 1992 & 39 & 0.195 & 1.17 & 1998 & 88 & 0.44 & 2.64 \\
\hline 1993 & 230 & 0.65 & 3.9 & 1999 & 98 & 0.49 & 3.04 \\
\hline 1994 & 108 & 0.54 & 3.24 & 2000 & 139 & 0.7 & 4.17 \\
\hline 1995 & 32 & 0.16 & 0.96 & 2001 & 72 & 0.36 & 2.16 \\
\hline 1996 & 207 & 1.035 & 6.21 & 2002 & 64 & 0.32 & 1.92 \\
\hline 1997 & 215 & 1.075 & 6.45 & 2003 & 63 & 0.315 & 1.89 \\
\hline
\end{tabular}

Source: Data from 1992 to 1997 are from the Contract Analysis in Financial Market written by Xianrong Yi, published by China City Press, Beijing. Data from 1998 to 2003 are from the website of China Security Regulatory Commission.

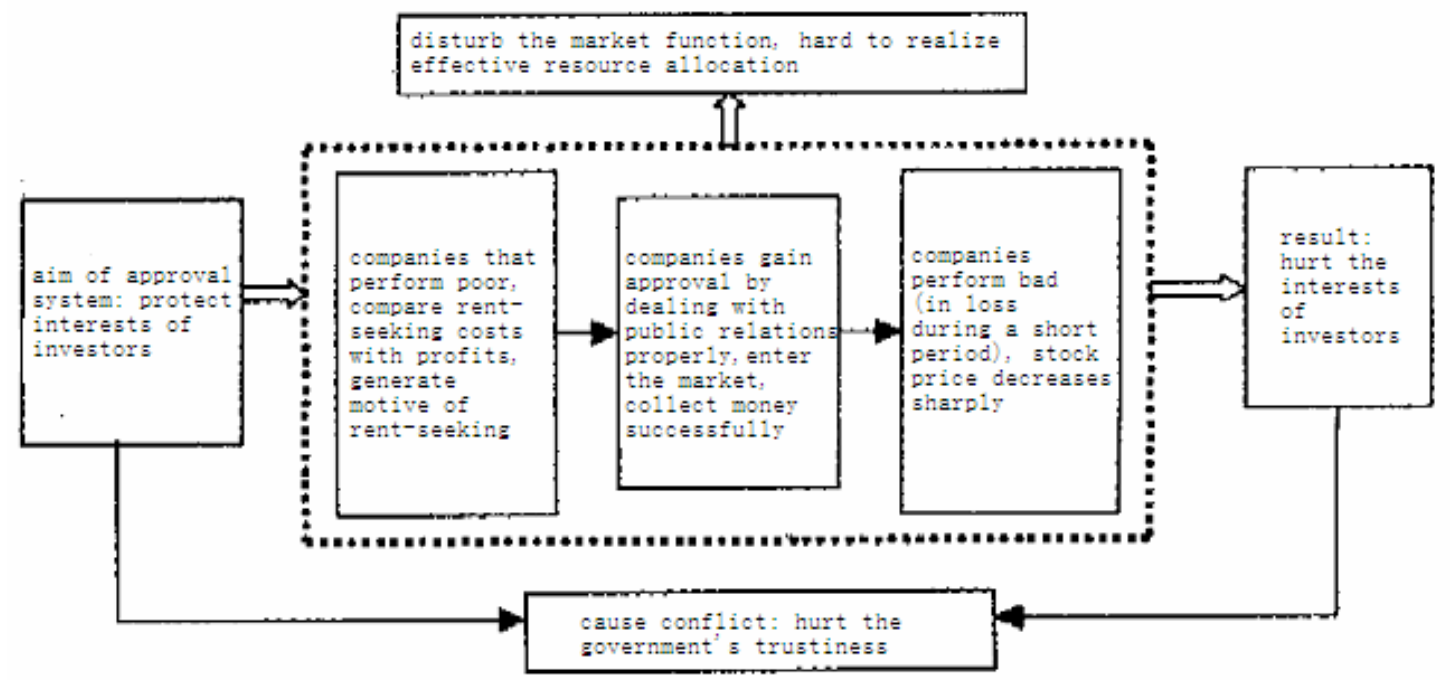

Figure 1 (Mingxian Liu, 2005). 


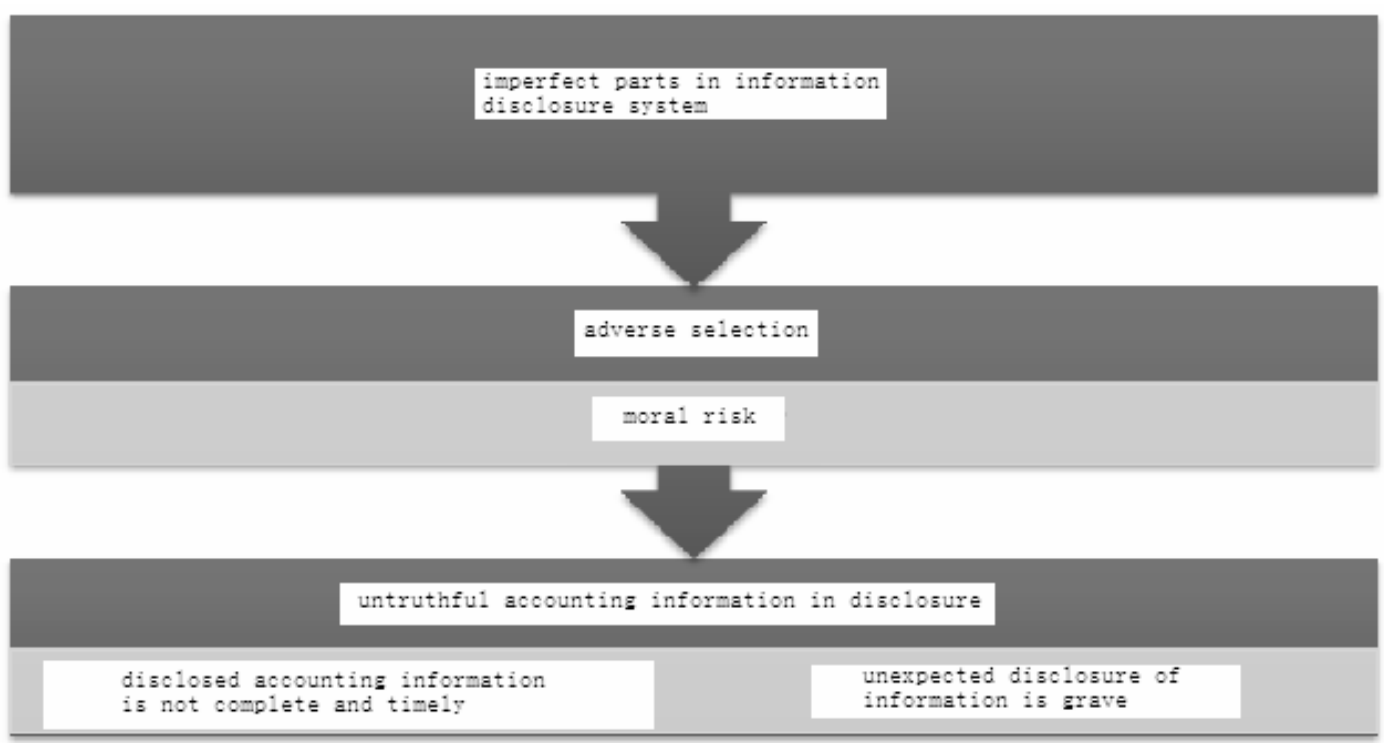

Figure 2.

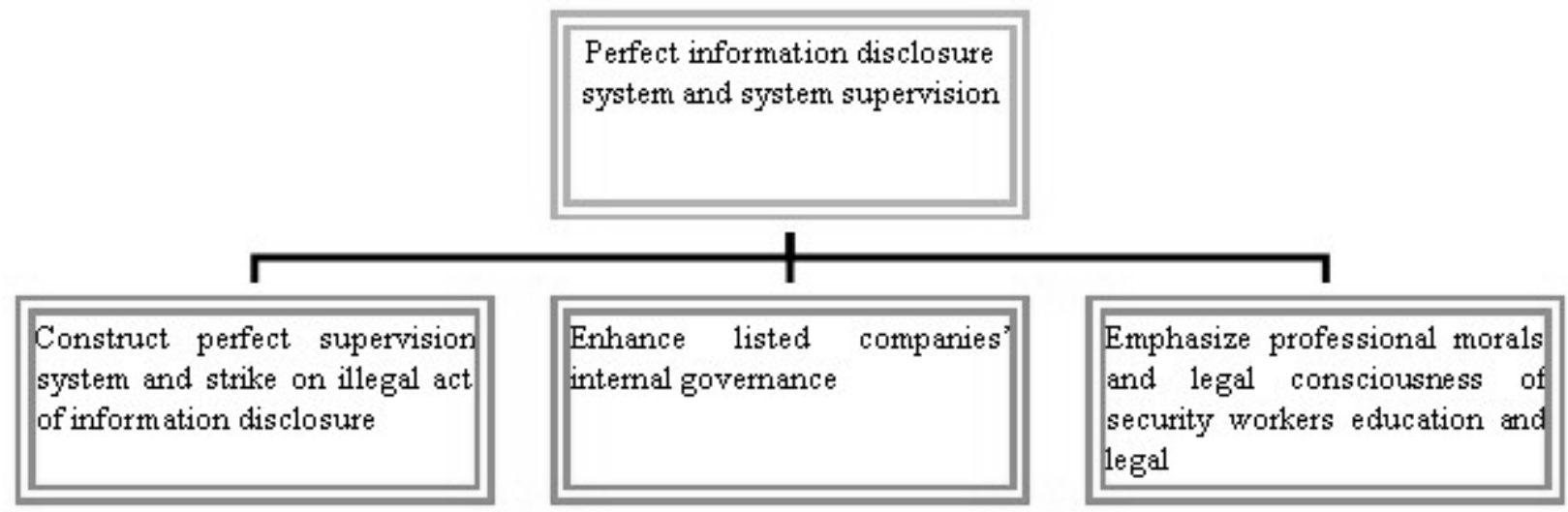

Figure 3.

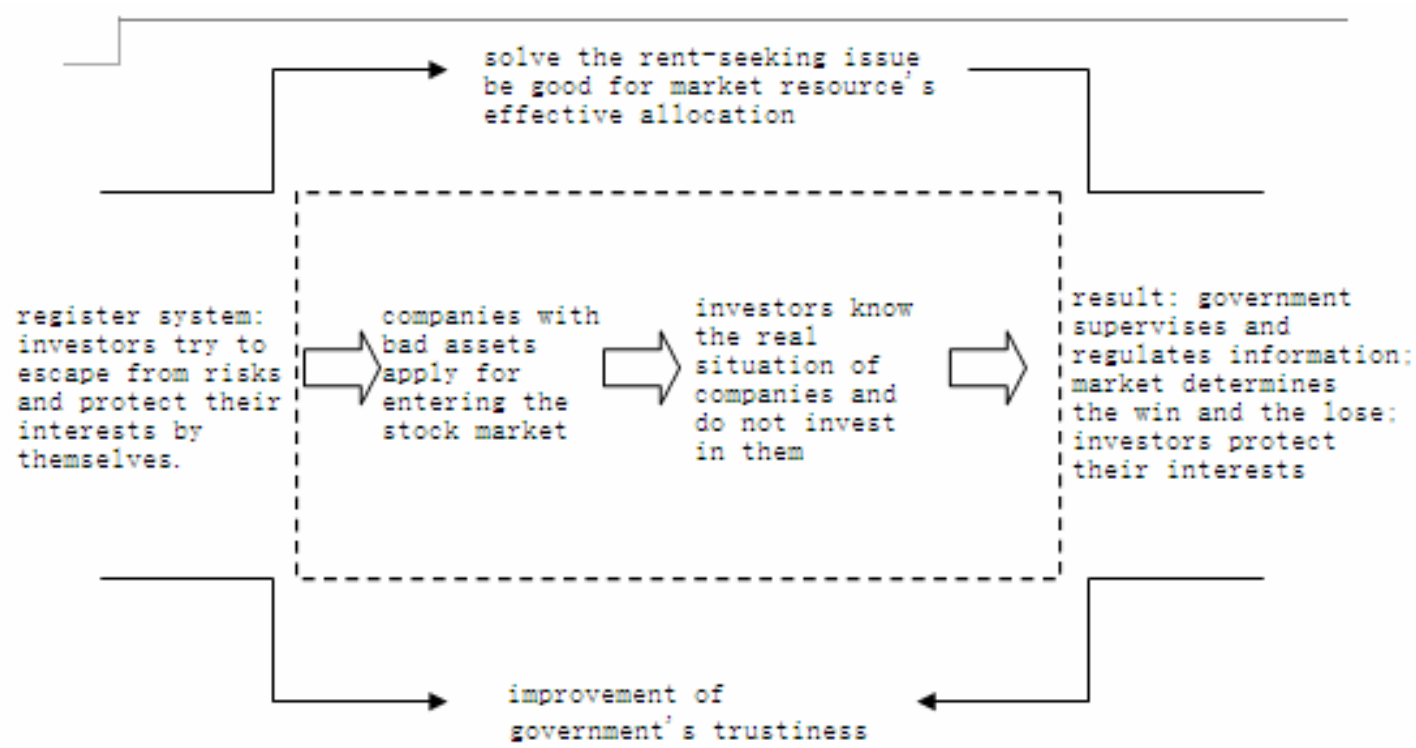

Figure 4. 